\title{
Current State of Knowledge on the Behavior of Steel Liners in Concrete Containments Subjected to Overpressurization Loads 1
}

\author{
W. A. von Riesemann \\ M. B. Parks \\ Sandia National Laboratories \\ Albuquerque, New Mexico USA 87185 \\ Facsimile: (505) 844-1648
}

\section{ABSTRACT}

In the United States, concrete containment buildings for commercial nuclear power plants have steel liners that act as the internal pressure boundary. The liner abuts the concrete, acting as the interior concrete form. The liner is attached to the concrete by either studs or by a continuous structural shape (such as a T-section or channel) that is either continuously or intermittently welded to the liner. Studs are commonly used in reinforced concrete containments, while prestressed containments utilize a structural element as the anchorage. The practice in some countries follows the U.S. practice, while in other countries the containment does not have a steel liner. In this latter case, there is a true double containment, and the annular region between the two containments is vented.

This paper will review the practice of design of the liner system prior to the consideration of severe accident loads (overpressurization loads beyond the design conditions).

\footnotetext{
1 For presentation at the 12th SMiRT Post-Conference on "Containment of Nuclear Reactors," Karlsruhe, Germany, August 23-24, 1993.

This work was supported by the U.S. Nuclear Regulatory Commission and performed at Sandia National Laboratories, which is operated by the U.S. Department of Energy under contract number DE-AC0476DP00789.
} 
An overpressurization test of a 1:6-scale reinforced concrete containment at Sandia National Laboratories resulted in a failure mechanism in the liner that was not fully anticipated. Post-test analyses and experiments have been conducted to understand the failure better. This work and the activities that followed the test are reviewed. Areas in which additional research should be conducted are given.

\section{INTRODUCTION}

In most countries, light water reactor (LWR) commercial power plants have a containment building that has a multitude of functions. Among these functions are: It acts as a barrier to external threats, and it contains any fission products that may be released from the primary system. The containment is the so-called "last barrier." The other barriers include the fuel-cladding and the primary pressure system. The containment building may be constructed of steel or concrete (reinforced or prestressed), and it may consist of a double containment system. The outer "containment" may be a shield building, or as is the case in some of the French systems, may be a combination shield and leak barrier.

The attention of this paper is restricted to concrete containments and to the practice in the United States, though much of the material is applicable to containments in other countries. In the U.S., all concrete containments are lined with steel plate that acts as the pressure boundary. In a way, the liner is like a bladder similar to the inner tubes that were used originally in pneumatic automobile and bicycle tires.

The steel liner abuts the concrete, acting as the interior form for the concrete. The liner is "attached" to the concrete by either studs or by a continuous structural shape.

\section{SCOPE OF PAPER}

The primary purpose of this paper is to assimilate and present the current state of knowledge on the behavior of steel liner systems (that is, the liner and the anchorage), and to suggest areas in which additional work is required. It is also the hope of the authors that 
this paper will encourage other investigators to come forth and add their knowledge to the subject matter.

The term failure of the containment (or in a broader sense the containment system) is used to describe different phenomena by different authors. The definition used herein is: failure is that point at which the containment system is no longer able to act as a pressure retaining boundary. Hence, failure may be loss of structural capacity/integrity or leakage through the mechanical or electrical penetrations, equipment hatches, and personnel air locks (especially those with inflatable seals), or in the case of concrete containments, failure of the liner to be able to retain pressure. This latter behavior is the focus of this paper.

Since the purpose of this paper is to give a summary, details will in most cases not be given; rather, they can be examined in the references. In addition, only a limited number of references are cited; however, these references contain many additional references. There are a number of reasons for not getting into the details. The primary one is that the authors feel that the global viewpoint should be emphasized. Most papers on the subject matter have addressed a specific topic, but have not discussed how the results apply to the complete understanding of the behavior of the liner system.

The major topics of this paper are:

a) Mid-70's - In this time period, there was a considerable amount of work devoted to the design of the liner system, primarily buckling of the liner plate. The loadings considered (pressure and temperature) were the design conditions corresponding to a LOCA (loss-of-coolant accident).

b) Early 80's - In this time period, separate effects tests on liner behavior were initiated, and the round-robin pre-test analyses of the Sandia 1:6-scale concrete containment test were undertaken.

c) 87 - Present - The investigations since the above test was conducted in 1987.

d) Future work - Topics that the authors feel need additional work. 


\section{MID-70'S}

The rules for the design of the liner-anchorage system were developed in this time period and are given in ASME Section III, "Rules for Construction of Nuclear Power Plant Components," Division 2, "Code for Concrete Reactor Vessels and Containments," Subsection CC, "Concrete Containments (Prestressed or Reinforced)." Articles CC-2500, $-2600,-2700,-3600,-3700,-3800,-4500,-4600$, and -5500 cover liner material, design, fabrication, and inspection.

The liner is assigned no strength in the design calculations. This is acceptable for the design conditions of this time period. However, if higher internal overpressurization loads are considered, the actual structural capacity of the liner must be used to properly account for the load distribution. Depending on the design, the liner can account for up to $20 \%$ of the hoop strength of the containment.

Before severe accidents became a concern, the major loads that were considered were: loads occurring during fabrication of the liner and placement of the concrete, LOCA loads (pressurization and thermal), and local loads due to the failure of an internal steam line (commonly called the jet-impingement load). These loads could cause buckling (global or local) of the liner, and many papers were written during this time period on this topic. At the Indian Point PWR, a steam line did break, and the liner did buckle without causing any tears in the liner.

To add some perspective to these studies and statements, the liner plate is typically between 1/4- and 3/8-inch (6- to $10-\mathrm{mm}$ ) thick, and is fabricated from a mild steel, such as ASTM A-516, with large ductility (on the order of $30 \%$ elongation). The diameters of the containments are in the 100 -foot $(30-\mathrm{m})$ range, which means that the $\mathrm{R} / \mathrm{t}$ ratio for the liner is on the order of 3000-5000. The design pressures for the concrete pressurized water reactor (PWR) containments range from 40 to $60 \mathrm{psig}(0.28$ to $0.41 \mathrm{MPa})$. The design temperature is about $350^{\circ} \mathrm{F}\left(175^{\circ} \mathrm{C}\right)$. The leak rate requirements for the liner are very stringent, and early efforts were directed toward detection methods for locating leakage 
points during leak testing. The design specifications for most plants allow a leakage area that is only slightly larger than the size of the period at the end of this sentence.

Also during this time period, tests were conducted on prestressed concrete reactor vessels, primarily in the United Kingdom, that have a much higher design pressure and $\mathrm{R} / \mathrm{t}$ ratio (for both liner and wall thickness). Some tests included liners. However, the results could only be used qualitatively for LWR containments.

Reference 1 contains a concise statement on the buckling of the liner: "ASME Section III, Division 2 permits liner buckling, but requires that liner-liner anchorage system analyses be performed in order to predict strains in the liner (membrane and flexural) and displacements of the anchorage system. The resulting liner strains and anchor displacements are required to be within Code allowables. These criteria preclude a liner failure or progressive anchor failure."

In essence, the design of the liner/anchorage system was based on the philosophy that the liner must be anchored to the concrete, buckling strains and deformations shall be limited, and that the anchorage should fail without tearing the liner. There were simple shear tests conducted on the liner-stud-concrete to show that the stud failed before tearing the liner. There was also a simple "hammer test," in which the stud was hit a glancing blow by a hammer to show that the liner did not tear, but rather that the stud bent over.

Some representative papers from this time period are References 2-9.

\section{EARLY 80's (to 1987)}

The accident at the Three Mile Island (TMI) nuclear power plant on March 28, 1979, was the beginning of a new time period for questions on containment performance, including the potential containment pressure and temperature levels in a severe accident. Because of the TMI accident, there has been worldwide attention on severe accidents and on the behavior of containments during these events. In actuality, there was some research on "severe accidents" before TMI, but it is fair to say that TMI focused the research. 
In 1982, the U.S.Nuclear Regulatory Commission began the "Containment Integrity Progranı" at Sandia; Reference 10 gives a recent summary of the activities of this program. The work on the reinforced concrete $(\mathrm{RC})$ containment model is particularly applicable to this paper.

A 1:6-scale model of a typical U.S. reinforced concrete containment was designed, constructed, and tested under pneumatic internal pressurization in July 1987 (Ref. 11). The design and fabrication followed the ASME Code as closely as possible.

While the round-robin pretest analyses (Ref. 12) concentrated on the overall structural behavior, many of the analysts (10 organizations took part in the full exercise) felt that failure may occur due to liner failure. The introduction to the pretest report (Ref. 12, which was issued before the test) contained the following sentence on page 6: "The possibility of local liner failure is recognized as a major uncertainty in the analysis by nearly everyone." However, because of time and money restraints, most organizations did not concentrate on the liner. There was also a false sense of security in that shear tests of the liner-anchorage system, conducted before the pressure test, resulted in shear failure of the studs rather than liner tearing. Also, it was known that the ductility of the liner material was high. In addition, if one evaluates the strain concentration values around the openings, the resulting values are on the order of $3-4$, but there was still the feeling that local liner failure was a possibility. In part, this was due to results of tests that were sponsored by the Electric Power Research Institute (EPRI), which are discussed below.

In performing the pretest analyses, assumptions on the strength of the basematcylinder intersection had to be made. As it turned out, the strength was underestimated. This is not too surprising, since design codes are known to be conservative, but the degree of conservatism is not known. However, the point that should be recognized is that, because of this assumption, the liner in this region was predicted to be a likely failure area. In other words, liner behavior is dependent on the behavior of the entire structure, and any uncertainty will affect the ability to predict liner tearing. 
The result of the 1:6-scale test, in brief, was failure (excessive leakage) of the containment caused by several tears of the liner at mid-height near or at the penetrations. The major tear was next to the thickened insert plate near the "steam lines." There were also tears in the sloping section of the liner at one of the equipment hatches. The thickened portion of the concrete wall for this hatch was symmetric about the center line; therefore, there is a sloping surface on the inside. The leakage at the time the test was terminated was approximately 5000\% mass/day (4000 standard cubic feet per minute). Complete test results are given in Reference 13. Of importance is that the failure did not occur in any heat affected zones caused by welding, and also, due to the number of tears, the failure was not caused by any problems in workmanship.

"As the model was pressurized, the walls moved radially outward and were stretched in the hoop direction. Because the insert plate is thicker, it tends to stretch much less that the thinner liner. The hoop reinforcement is continuous through this region, so it stretches uniformly. As a result, there is a natural 'slippage' between the liner and the concrete wall. The studs, which are imbedded in the concrete, want to follow the motion of the concrete wall. However, because the base of the studs is welded to the liner, the studs resist this slippage and by doing so impose a local 'point' load on the liner at their base. It is believed that this additional liner load caused by the studs is the main reason for the..." major liner tear at this location (Ref. 14).

When it was determined that the model would not be re-pressurized, portions of the liner were removed mechanically to observe the studs and concrete (Ref. 15).

Before and during the Sandia activity on the 1:6-scale model, EPRI sponsored a series of experiments at Construction Technology Laboratories (CTL) and analyses at ANATECH. In contrast to the Sandia test, which was a scale model of the complete containment, the EPRI work, which is complementary to the NRC-sponsored work, followed the philosophy of testing either full-size or nearly full-size flat panels that represent parts of the containment wall. It should be noted that both methods (full-size 
portions vs. models) have limitations. In the former, there is the concern about boundary conditions, while in the latter, there are similitude concerns. The EPRI-sponsored tests were conducted in a special testing frame constructed at CTL. The dominant mode of failure in these tests was liner failure. The first phase of the program was conducted in 1982-83 on simple biaxial slabs and liners (Ref. 16). Many reports have been issued on the EPRI work; Reference 17 is the most recent report. T' 1 he analytical work, combined with insights from the experimental work, showed the importance of the behavior of liner tearing as a possible source of containment failure.

\section{87 - PRESENT}

The next time period begins after the results of the 1:6-scale containment test were interpreted. The examination of the major tear showed that the tear followed the first row of studs adjacent to the thickened insert plate. Analyses of this region were conducted by a number of groups (SNL, EPRI, CEA, NII, ENEA, AEA, and GRS)' as part of the posttest evaluations. Models were employed with varying complexity and a diverse array of approaches with significant differences in the mathematical model details, including some limited three-dimensional models. "Yet, despite the broad differences in the analytical approaches, there are many similarities" (Ref. 18).

As stated before, "the insert plates used around penetrations by themselves cause local strain concentrations two to four times the free field strain" (Ref. 18). However, this is not sufficient to cause a tear in the liner.

The additional feature is the studs imposing significant loads to the liner due to the slippage at the insert plate, as discussed above. With the studs modeled, SNL, CEA, and GRS calculated liner strain concentrations of ten or more times the free field strain near the maximum test pressure. GRS considered several different models for liner tearing,

${ }^{1} \mathrm{CEA}=$ Commissariate a L'Ènergie Atomique, France; NII = Health \& Salety Executive, Nuclear Installations Inspectorate, United Kingdom; ENEA = Energia Nucleare e delle Energic Alternative, Italy; $\mathrm{AEA}=$ Atomic Energy Authority, United Kingdom; and GRS = Gesscllschaft für Anlangen- und Reaktorsicherheit, Germany. 
including one in which the stud embedment in the concrete was explicitly modeled. CEA performed an interesting sensitivity study; by removing the first row of studs on the nominal thickness liner next to the insert plate, they found that the maximum local strain was reduced by about half. SNL conducted additional calculations to understand the stud behavior that provided two interesting conclusions.

1. When the liner is not subject to membrane yield loads prior to the application of high stud shear forces, the failure mode is expected to be stud failure instead of liner tearing." ... "Liner membrane yield loads, which in an actual containment precede the development of high stud shear loads, must be represented.

2. Strains calculated with a plane stress model where the stud shear forces are modeled as point loads can be reasonably interpreted as average strains through the liner thickness..." (Ref. 18)

"To interpret the calculated liner strains, SNL, EPRI, ENEA, and GRS all adopted the same criterion for evaluating the liner ductility under biaxial loads, which is based on the Davis triaxiality factor. ANATECH is credited with the initial use of this criterion to containment liners" (Ref. 13). GRS had previously used it for a steel containment shell.

To further study the parameters that affect liner tearing, uniaxial tests were conducted on a series of models. These specimens were flat panels that represented certain features of the 1:6-scale Sandia model. Strain gages and photoelastic coatings were used (Ref. 19). Analyses of these separate effects tests have also been conducted (Ref. 20, 21).

There are several interesting conclusions. In one series of tests, six separatelycontrolled loading specimens were tested, with each test being conducted using a different liner preload. Al lower preloads the studs failed, while at higher preloads the liner failed. This explains the false impression that one gathered from the early shear tests in which only the stud failed. Analyses of these tests essentially confirmed the experimental results, except that the calculations are somewhat sensitive to the assumed stud shear strength. 
Another test series was conducted in which an attempt was made to reproduce the mechanism that caused liner tearing in the 1:6-scale containment. The specimen included the liner and insert plate with studs attached, representative reinforcement, and concrete to represent a section through the wall of the 1:6-scale containment. Unfortunately, these tests were unsuccessful in replicating the exact behavior that caused the main liner tear in the 1:6-scale containment. Although the liner tore at the same relative location as in the containment model, the amount of elongation required to cause the tear was considerably higher. This difference in behavior is believed to be caused by the lack of lateral restraint to the concrete in the uniaxial specimen after concrete cracking occurs, which allowed the studs to move "out of the way" of the concrete without transferring the full "slip" or shear load to the liner. In the containment model, the concrete is confined in all directions, which leads to more effective shear transfer from the studs to the liner.

Analyses have also been conducted in France on the behavior of a liner in the vicinity of a penetration in a $900 \mathrm{MWe}$ PWR (Ref. 22). The conclusion was that at 10 bar pressure, tears will not occur because of the "low level of plastic deformation." At 12.5 bar (near the ultimate pressure) studs near the insert show "strong plastic deformation." Further study "... seems necessary to get a better insight for evaluating the link between the stud and the liner."

\section{FUTURE WORK}

Based on an evaluation of the work completed to date, the following topics are candidates for future work. The list is not inclusive, nor in order of priority.

1. For liner plates that use stud anchors, the effect of varying the stud spacing, the location of studs near discontinuities, stud strength, and the relative thickness of the insert plate to the nominal liner thickness must be investigated.

2. Before and after the upcoming test of a prestressed concrete containment, through a cooperative program between the Nuclear Power Engineering Corporation (NUPEC), 
the NRC, and Sandia, the behavior of line anchorage should be studied by analysis and by conducting separate effects tests.

3. Thermal effects should be studied. There have been at least two thermal tests (EPRI and Japan) of a section of a liner plate, but a verified analytical method still needs to be developed.

4. The ASME code committee should reexamine the requirements for liner systems. In particular the ultimate behavior of the system should be considered. Spacing between anchors and halting anchorage at some distance from a discontinuity are but a few of the potential areas for investigation.

5. The need and reasons for anchorage should be reexamined in today's light.

\section{ACKNOWLEDGMENTS}

This paper is based on the work of many individuals and organizations. The authors would like to acknowledge the work of our many colleagues at Sandia National Laboratories and the leadership and foresight that Dr. James F. Costello of the U.S. Nuclear Regulatory Commission has provided to the Containment Integrity Program at Sandia. We would also like to acknowledge our peer review committee and the work of the people throughout the international community.

\section{DISCLAIMER}

\footnotetext{
This report was prepared as an account of work sponsored by an agency of the United States Government. Neither the United States Government nor any agency thereof, nor any of their employees, makes any warranty, express or implied, or assumes any legal liability or responsibility for the accuracy, completeness, or usefulness of any information, apparatus, product, or process disclosed, or represents that its use would not infringe privately owned rights. Reference herein to any specific commercial product, process, or service by trade name, trademark manufacturer, or otherwise does not necessarily constitute or imply its endorsement, recommendation, or favoring by the United States Government or any agency thereof. The views and opinions of authors expressed herein do not necessarily state or reflect those of the United States Government or any agency thereof.
} 


\section{REFERENCES}

[1] Prepared by: ASCE Nuclear Structures and Materials Committee, Materials and Structural Design Committee, J.J. Uciferro, Chairman "Containment Capability," in: Structural Engineering in Nuclear Facilities, Vol. 2, Proceedings of Conference at North Carolina State University (September 1984) pp. 948-1011, Section 3.0 Concrete Containment Liner, pp. 977-988.

[2] Report by Bechtel, "Containment Building Liner Plate Design," BC-TOP-1, Bechtel Corporation, (1972).

[3] E.G. Burdette, "Second Interim Report on Liner Anchorage Tests," TVA Contract No. TV-37807A, Civil Engineering Branch, Bellefonte Nuclear Plant (September 1974).

[4] T.P. Kicher and M.J. Schrader, "Design Selection of Patterns and Spacings for Stud Anchors Used on Liner Shells," in: Structural Design of Nuclear Plant Facilities, Second ASCE Specialty Conference on New Orleans, Louisiana, USA (December 1975). Vol. 1-B, pp. 1366-1409.

[5] K.P. Buchert, "Structural Performance Predictions for Liner Plates on Nuclear Facilities," in: Structural Engineering in Nuclear Facilities, Proceedings of Conference at North Carolina State University, Raleigh, North Carolina, USA (September 1984) Vol.2, pp. 887-893.

[6] P.L. Chang-lo, T.E. Johnson, and B.W. Pfeifer, "Containment Liner Plate Anchors and Steel Embedments Test Results," in: SMiRT 4, J5/9.

[7] F. Buchardt and P. Brandl, "Untersuchungen zur Integrität des Liners von Reaktorsicherheitshüllen (Containments) in Stahlbeton- und Spannbetonbauweise," ISSN 0172-7613, Forshungsbericht 69, Bundesanstalt für Materialprüfung (BAM), Berlin (June 1980). 
[8] F. Buchardt, and P. Brandl, "A Realistic Structural Analysis of the Integrity of the Liner of Reinforced and Prestressed Concrete Containments," in: SMiRT 5, J3/4.

[9] B.W. Wedellsborg, "Two-Dimensional Nonlinear Analysis of Steel Liner and Anchorage Systems for Post-Tensioned Concrete Containment Buildings," in: SMiRT 6, J6/3.

[10] M.B Parks, et al., "Summary of NRC Sponsored Research on Containment Integrity," in: Smirt 11, SDO1/3.

[11] D.S. Horschel, "Design, Construction, and Instrumentation of a 1:6-Scale Reinforced Concrete Containment Building," NUREG/CR-5083, SAND88-0030, Sandia National Laboratories, Albuquerque, NM (August 1988).

[12] D.B. Clauss, (ed.), "Round-Robin Pretest Analyses of a 1:6-Scale Reinforced Concrete Containment Model Subject to Static Internal Overpressurization," NUREG/CR-4913, SAND87-0891, Sandia National Laboratories, Albuquerque, NM (April 1987).

[13] D.S. Horschel, "Experimental Results from Pressure Testing of a 1:6-Scale Nuclear Power Plant Containment," NUREG/CR-5121, SAND88-0906, Sandia National Laboratories, Albuquerque, NM (January 1992).

[14] Parks, M.B., et al., “Containment Performance Experiments Under Severe Accident Loadings," Proceedings of the 19th Water Reactor Safety Meeting, Bethesda, MD (October 1991).

[15] L.D Lambert, "Posttest Destructive Examination of the Steel Liner in a 1:6-Scale Reactor Containment Model," NUREG/CR-5961, SAND92-1721, Sandia National Laboratories, Albuquerque, NM (February 1993).

[16] N.W. Hanson, J.T.Julien, D.M. Schultz, "Tension Tests of Containment Wall Isolated Liner Plates," in: Structural Engineering in Nuclear Facilities, Vol. 1, pp. $555-573$. 
[17] J.C. Castro, et al., "A Probabilistic Approach for Predicting Concrete Containment Leakage," EPRI TR-102176, Final Report, Prepared by ANATECH Research Corporation for Electric Power Research Institute (March 1993).

[18] D.B. Clauss, (ed.), "Round-Robin Analysis of the Behavior of a 1:6-Scale Reinforced Concrete Containment Model to Failure: Posttest Evaluations," NUREG/CR-5341, SAND89-0349, Sandia National Laboratories, Albuquerque, NM (October 1989).

[19] J.R Weatherby, and D.B. Clauss, "Investigation of Liner Tearing Near Penetrations in a Reinforced Concrete Containment Under Severe Accident Loads," in: SMiRT 10, H02/5.

[20] B.L. Spletzer, and L.D. Lambert, "Separate Effects Testing to Investigate Liner Tearing of the 1:6-Scale Reinforced Concrete Containment Building," in: SMiRT 12, $\mathrm{J} 05 / 2$.

[21] V.L. Bergmann, J.R. Weatherby, and M.B. Parks, "Analysis of Separate Effects Tests for Liner Tearing in the 1:6 Scale Model of a Reinforced Concrete Containment Building," in: SMiRT 12, U03/3.

[22] B. Barbe, et al., "Local Study of the Liner of a Prestressed PWR Containment in the Vicinity of Penetrations," in: SMiRT 11, J01/4. 

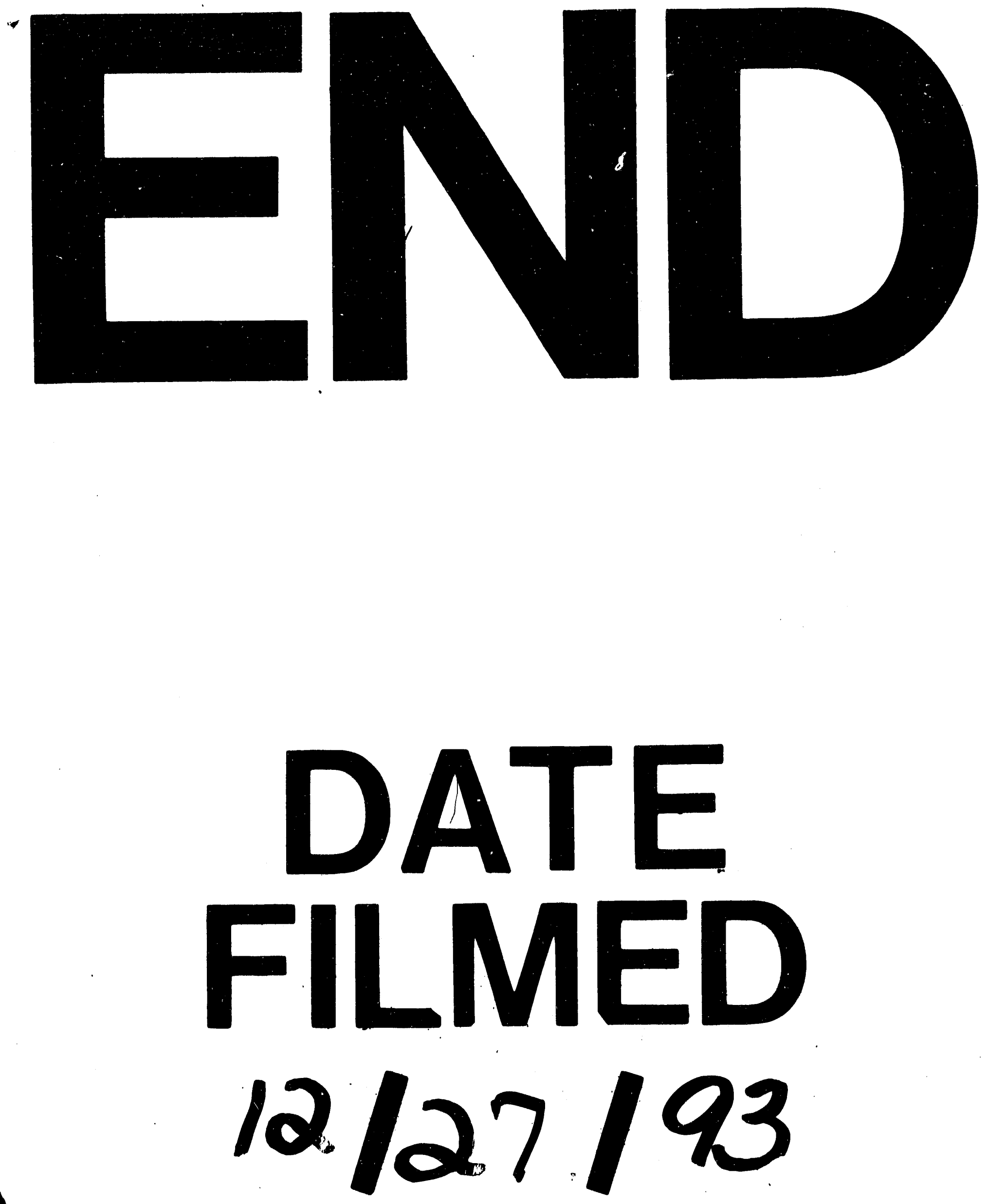

【 
